\title{
Sistem Keamanan Rumah Menggunakan RFID, Sensor PIR dan Modul GSM Berbasis Mikrokontroler
}

\author{
${ }^{1}$ Ade Mubarok, ${ }^{2}$ Ivan Sofyan, ${ }^{3}$ Ali Akbar Rismayadi, ${ }^{4}$ Ina Najiyah \\ ${ }^{1}$ Universitas BSI \\ e-mail: ade.amb@bsi.ac.id \\ ${ }^{2}$ Universitas BSI \\ e-mail: ivansofyan95@gmail.com \\ ${ }^{3}$ Universitas BSI \\ e-mail: ali.aak@bsi.ac.id \\ ${ }^{3}$ Universitas BSI \\ e-mail: ina.iaj@bsi.ac.id
}

\begin{abstract}
Abstrak
Keamanan merupakan hal sangat penting bagi setiap orang. Rumah yang sering ditinggal pemiliknya dapat dimanfaatkan oleh pencuri untuk melakukan aksinya. Oleh karena itu diperlukan sistem keamanan rumah yang efektif agar pemilik rumah dapat mengetahui informasi apabila rumahnya dibobol oleh pencuri. Penulis merancang sebuah sistem keamanan rumah dengan memanfaatkan teknologi RFID yang di lengkapi dengan sensor PIR dan modul GSM sebagai sistem informasi peringatan SMS, dimana semua sistemnya diolah dalam sebuah mikrokontroler ATmega328. Tujuan dari penelitian ini untuk mengganti kunci konvesional dengan kunci solenoid sehingga sulit untuk diduplikat serta mengurangi kesempatan aksi pencurian ketika rumah dalam keadaan kosong. Metode penelitian yang digunakan antara lain dimulai dari pengumpulan data (observasi, wawancara dan studi pustaka) serta pembuatan alat (planning, analisis, desain dan testing). Berdasarkan hasil pengujian diperoleh bahwa kunci solenoid dapat bekerja sesuai dengan kartu akses RFID yang diberikan. Sensor PIR dan modul GSM dapat bekerja dengan baik saat pencuri masuk kedalam rumah, sehingga rumah menjadi aman ketika ditinggalkan oleh pemiliknya.
\end{abstract}

Kata Kunci: RFID, Sensor PIR, Modul GSM, ATmega328

\begin{abstract}
Security is very important for everyone. Homes that are often left the owner can be used by thieves to perform the action. Therefore required an effective home security system so that homeowners can find out information if the house burglarized by thieves. The author designed a home security system by utilizing RFID technology that is equipped with PIR sensor and GSM module as SMS warning information system, where all the system is processed in an ATmega328 microcontroller. The purpose of this research is to change the conventional key with the solenoid key so that it is difficult to duplicate and reduce the chance of theft action when the house is empty. Research methods used, among others, starting from data collection (observation, interview and literature study) as well as making tools (planning, analysis, design and testing). Based on the test results obtained that the solenoid key can work in accordance with the given RFID access card. PIR sensors and GSM modules work well when thieves enter the house, so the house becomes secure when left by the owner.
\end{abstract}

Key Word: RFID, PIR Sensor, GSM Module, ATmega328

\section{Pendahuluan}

Menurut data dari Badan Pusat Statistik (2016) selama periode tahun 20132015 aksi kejahatan pencurian rumah tangga di Indonesia terus mengalami peningkatan. Jumlah rumah tangga yang menjadi korban kejahatan pencurian di Indonesia tahun 2013 sebanyak 1.058.289 rumah. Pada tahun 2014 kejahatan pencurian meningkat dengan jumlah 
sebanyak 1.258.973 rumah. Pada tahun 2015 kejahatan pencurian meningkat lagi dari tahun sebelumnya yaitu sebanyak 1.405.562 rumah. Kurangnya tingkat keamanan dan mahalnya biaya pengaman ekstra menjadi seringnya terjadi pencurian pada rumah.

Keamanan rumah merupakan salah satu hal yang penting dalam kehidupan. Setiap manusia membutuhkan jaminan keamanan yang lebih pada tempat tinggal mereka seperti halnya kesehatan. Berbagai macam pengembangan dalam bidang teknologi dirancang untuk memberikan keamanan bahkan melindung aset yang dimiliki, sehingga diharapkan dengan sistem keamanan yang dirancang dapat memberikan rasa aman dan nyaman. Selain hal tersebut tentunya dengan sistem keamanan yang akan dirancang ini dapat mengurangi angka kriminalitas yang terjadi di masyarakat khususnya tindak kejahatan pencurian (Tempongbuka et al., 2015).

Pada zaman sekarang tindak kejahatan tidak dapat dipisahkan dari kehidupan sehari-hari di karenakan sebuah aksi kejahatan dapat terjadi kapan saja dan dimana saja ketika pelaku memiliki kesempatan, salah satunya seperti aksi pencurian didalam rumah. Kejadian tersebut sering terjadi dengan cara merusak atau membobol sistem kunci pada pintu maupun jendela yang merupakan akses utama untuk keluar masuk rumah. Bahkan kasus pencurian juga sering terjadi walaupun pemilik rumah sedang berada didalam rumah. Meskipun pintu sudah dikunci namun pencuri tetap saja dapat mengakali kunci pintu tersebut hanya dengan menggunakan sebatang kawat dan obeng saja. Dengan tingginya angka kriminalitas khususnya pencurian yang terjadi saat ini maka sistem keamanan rumah menjadi kebutuhan yang mutlak untuk diterapkan (Rerungan et al., 2014).

Salah satu inovasi teknologi sistem keamanan yang dilakukan oleh (Undala et al.,2015) yaitu sistem keamanan pintu mengggunakan RFID dengan kata sandi dimana alat hasil rancangannya tersebut memiliki sistem yang dapat memverifikasi identitas user pada kartu RFID dan kata sandi menggunakan mikrokontroler ATmega16 sehingga dapat menggerakan motor servo sebagai pengunci pintu otomatis. Keterbatasan dari alat ini adalah tidak bisa mendeteksi pergerakan orang dan tidak memiliki sistem informasi peringatan ketika rumah dimasuki oleh pencuri.

\section{Rangkaian Dasar Alat}

Rangkaian dasar alat terdiri dari komponen aktif dan pasif. Menurut Angga

(2015) komponen aktif merupakan komponen elektronika yang memerlukan arus listrik untuk dapat bekerja. Contoh dari komponen aktif diantaranya transistor, dioda, IC (Integrated Circuit) dan LED (Light Emitting Dioda). Sedangkan komponen pasif merupakan jenis komponen elektronika yang tidak memerlukan arus listrik untuk dapat bekerja. Contoh dari komponen pasif diantaranya resistor.

\section{RFID (Radio Frequency Identification)}

Menurut Undala et al., (2015) RFID adalah teknologi identifikasi berbasis gelombang radio. Teknologi ini mampu mengidentifikasi berbagai objek secara simultan tanpa diperlukan kontak langsung atau dalam jarak pendek. Menurut Rerungan et al., (2014:21) sensor RFID adalah sensor yang mengidentifikasi suatu barang dengan menggunakan frekuensi radio. Sensor ini terdiri dari dua bagian penting yaitu transceiver (reader) dan transponder (tag). Setiap tag tersimpan data yang berbeda. Data tersebut merupakan data identitas tag. Reader akan membaca data dari tag dengan perantara gelombang radio. Pada reader biasanya terhubung dengan suatu mikrokontroler. Mikrokontroler ini berfungsi untuk mengolah data yang didapat dari reader.

\section{Bahasa C}

Menurut Purnomo (2015) bahasa pemrograman untuk mikrokontroler AVR yang paling populer adalah menggunakan bahasa C. Bahasa C adalah bahasa pemrograman tingkat menengah. Selain bahasa $\mathrm{C}$ ada bahasa tingkat rendah seperti assembly dan bahasa tingkat tinggi seperti basic dan pascal. Semakin rendah bahasa pemrograman maka semakin mendekati kode mesin namun sulit dimengerti oleh manusia. Sebaliknya semakin tinggi bahasa pemrograman maka semakin mudah dimengerti oleh manusia namun sukar untuk diaplikasikan ke mesin, dalam hal ini adalah mikrokontroler.

\section{Relay}

Menurut Masinambow et al., (2014) relay adalah komponen elektronika berupa saklar elektronik yang digerakkan oleh arus listrik.

\section{Buzzer}

Menurut Sulistyowati dan Febriantoro (2012) buzzer adalah sebuah komponen 
elektronika yang berfungsi untuk mengubah getaran listrik menjadi getaran suara.

\section{LCD (Liquid Crystal Display).}

Menurut Gamayel dan Rizal dalam jurnal Riyadi dan Purnama (2013) LCD adalah salah satu komponen elektronika yang berfungsi sebagai tampilan suatu data baik karakter, huruf ataupun grafik. LCD banyak digunakan karena tampilannya menarik.

\section{Kunci Solenoid}

Menurut Asad et al., (2015) kunci adalah perangkat mekanik atau elektrik yang dikendalikan oleh suatu objek fisik (seperti kunci, kartu, sidik jari, kartu RFID dan token keamanan) yang berisi informasi rahasia. Menurut Guntoro et al., (2013:40) solenoid elektro mekanik bekerja ketika diberi tegangan $12 \mathrm{~V}$.

\section{Metode Penelitian}

Metode penelitian yang digunakan dimulai dari pengumpulan data dan pembuatan alat. Dalam metode pengumpulan data, penulis menggunakan beberapa teknik diantaranya:

\section{Observasi}

Penulis melakukan pengamatan dan pengembangan terhadap alat yang sudah ada.

\section{Wawancara}

Penulis melakukan wawancara berupa tanya jawab dengan dosen pembimbing dan orang-orang yang berkompeten dalam bidang mikrokontroler.

\section{Studi Pustaka}

Pada tahap studi pustaka penulis mencari data-data yang relevan diperoleh dari buku, jurnal dan ebook yang dapat menunjang dalam penelitian ini.

Metode pembuatan alat dilakukan dengan studi literatur dari perangkat yang akan digunakan dalam perancangan alat ini. Metode pembuatan alat tersebut mencakup beberapa hal diantaranya:

\section{Planning}

Pada pembuatan sistem keamanan rumah ini menggunakan RFID reader, sensor sentuh, dan sensor PIR sebagai alat input. Mikrokontroler ATmega328 sebagai sistem pengolah input dan output. Modul GSM, kunci solenoid, LCD, LED dan buzzer sebagai alat output.

\section{Analisis}

Tahap ini melakukan analisis untuk mengumpulkan data-data yang dibutuhkan dalam pembuatan sistem keamanan rumah. Desain
Mendesain hardware dan software untuk menjadikan sistem keamanan rumah modern dengan teknologi yang mudah dioperasikan oleh pengguna.

\section{Testing}

Pada tahap pengujian ini, agar dapat mengetahui alat berfungsi dengan baik adalah dengan cara menguji RFID, sensor PIR dan modul GSM. Apabila tag card ditempelkan pada RFID reader maka kunci solenoid rumah akan terbuka. Jika pemilik rumah mengirimkan sms dengan perintah "Alarm hidup" maka semua sensor PIR akan bekerja mendeteksi pergerakan orang didalam rumah.

\section{Implementasi}

Pada tahap ini alat yang sudah di uji akan diimplementasikan pada rumah. Hasilnya ketika ada pencuri masuk secara paksa ke dalam rumah maka alarm buzzer akan berbunyi dan mengirimkan SMS melalui modul GSM berupa informasi peringatan kepada pemilik rumah.

\section{Hasil dan Pembahasan}

Perancangan alat ini dibuat berdasarkan gambaran umum dan desain sistem untuk membuat rangkaian input, proses dan output. Sistem keamanan rumah yang dibuat merupakan pengembangan dari sistem keamanan yang sudah ada sebelumnya. Dibawah ini merupakan gambaran umum dari sistem keamanan rumah tersebut.

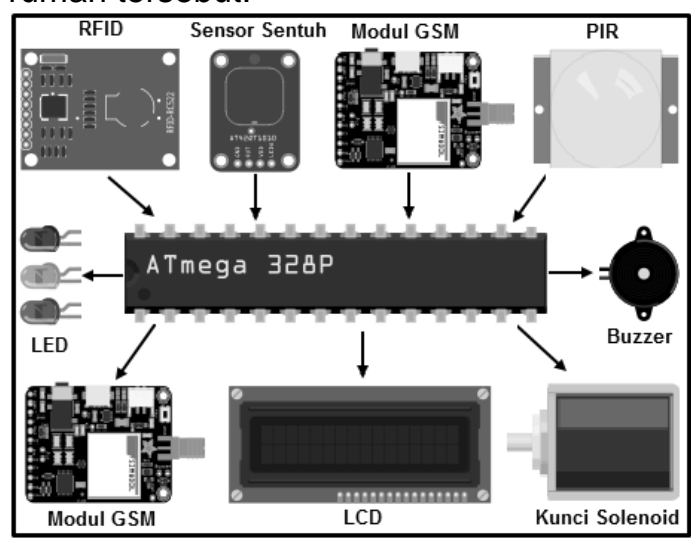

Gambar 1. Gambaran Umum

Gambaran umum diatas menjelaskan mengenai konsep proses sistem keamanan rumah, dimana input dari sensor RFID, sensor sentuh, modul GSM dan sensor PIR akan diproses oleh mikrokontroler ATmega328. Ketika kartu RFID atau sensor sentuh diaktifkan maka kunci solenoid akan membuka pintu rumah kemudian layar LCD dan lampu LED akan 
menampilkan indikator hak akses. Apabila pemilik rumah mengirimkan SMS ke modul GSM untuk mengaktifkan alarm, maka sensor PIR akan aktif bekerja. Jika ada pergerakan orang didalam rumah, sensor PIR akan mengirimkan sinyal ke mikrokontroler dan menghasilkan output peringatan SMS tanda bahaya melalui modul GSM ke nomor handphone pemilik rumah serta membunyikan alarm buzzer.

\subsection{Desain Sistem}

Desain sistem dibuat berdasarkan flowchart untuk menjelaskan alir diagram dari sistem keamanan rumah tersebut. Pembuatan flowchart untuk sistem keamanan rumah ini dibagi menjadi dua bagian yaitu flowchart kunci rumah dan flowchart alarm rumah.

\section{a. Flowchart kunci rumah}

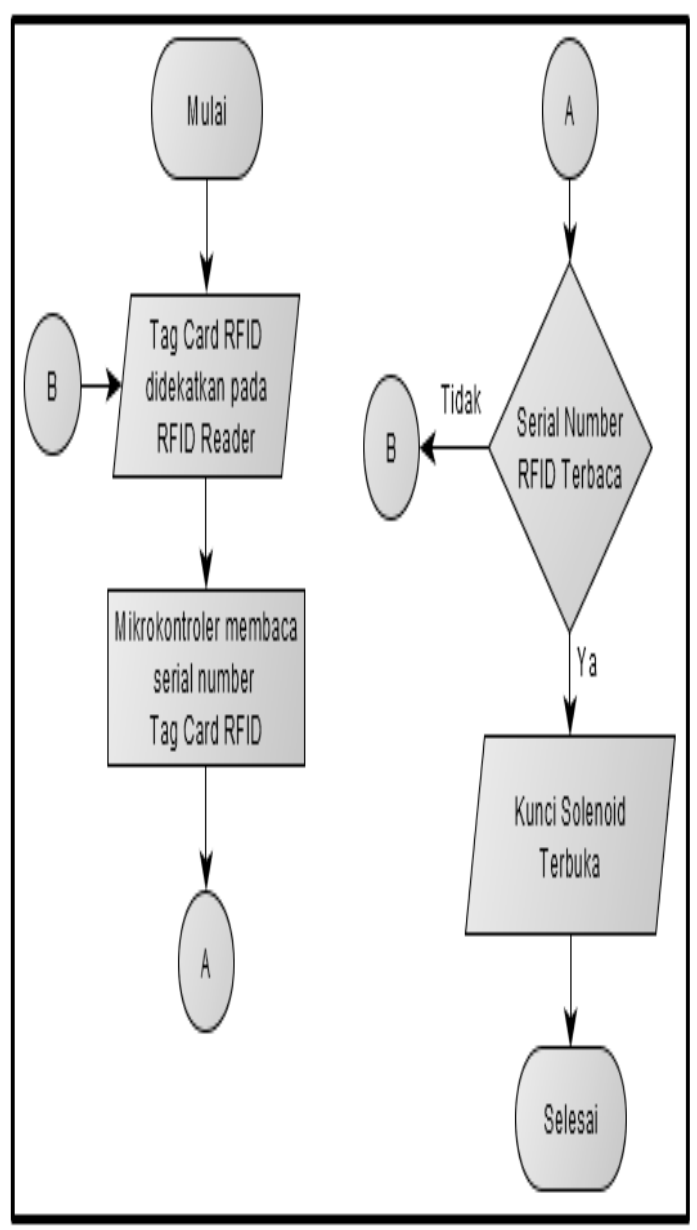

Gambar 2. Flowchart Kunci Rumah

Flowchart diatas menjelaskan mengenai proses penguncian pintu rumah. Awalnya tag card RFID didekatkan pada RFID reader. Kemudian mikrokontroler akan membaca serial number yang terdapat pada tag card RFID tersebut. Apabila serial number RFID terbaca oleh mikrokontroler dan tag card RFID tersebut hak aksesnya diterima maka kunci solenoid secara otomatis akan terbuka.

\section{b. Flowchart alarm rumah}

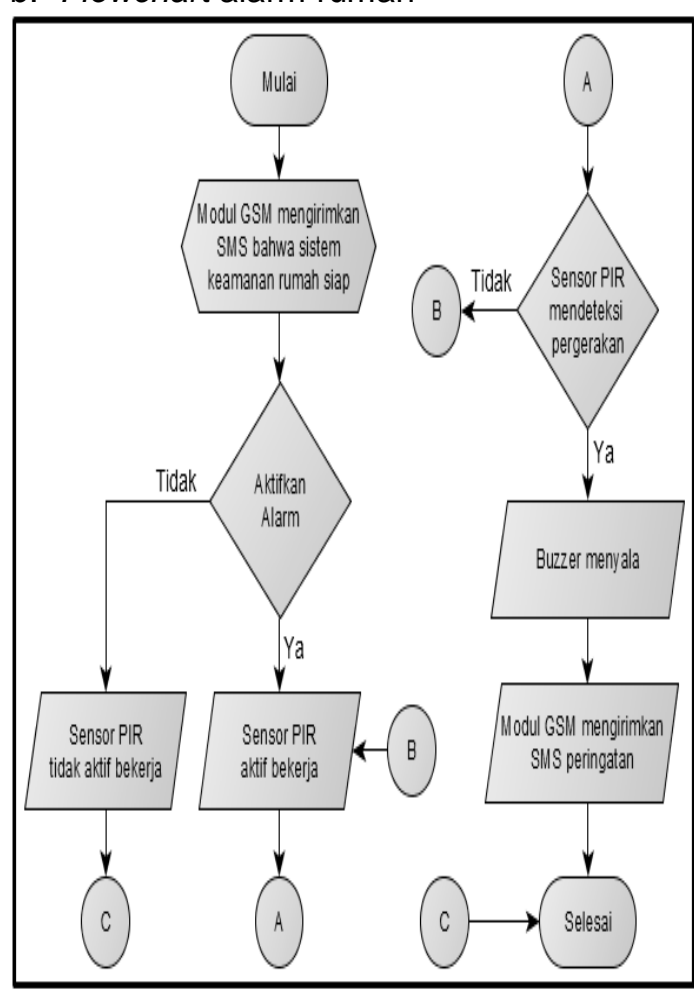

Gambar 3. Flowchart Alarm Rumah

Flowchart diatas menjelaskan mengenai proses sistem kerja alarm rumah. Awalnya modul GSM akan mengirimkan SMS kepada pemilik rumah bahwa sistem keamanan rumah siap. Apabila alarm dihidupkan maka sensor PIR aktif bekerja, sedangkan apabila alarm dimatikan maka sensor PIR tidak akan bekerja aktif. Ketika pemilik rumah menghidupkan alarm secara otomatis sensor PIR akan aktif bekerja untuk mendeteksi pergerakan orang didalam rumah. Jika ada pergerakan orang didalam rumah maka alarm buzzer akan menyala dan modul GSM mengirimkan SMS peringatan tanda bahaya ke nomor handphone pemilik rumah.

\subsection{Implementasi Sistem}

Agar memudahkan saat uji coba alat, dibuatlah sebuah prototype ruangan yang menyerupai rumah. Prototype yang dibuat terdiri dari ruang tamu, ruang tengah, dua kamar tidur, ruang dapur dan kamar mandi. Semua komponen rangkaian sistem diterapkan pada prototype yang telah dibuat. RFID reader, sensor sentuh dan kunci solenoid ditempatkan pada ruang tamu, 
sensor PIR ditempatkan pada masingmasing ruangan yaitu ruang tamu, kamar tidur dan ruang dapur, sedangkan komponen rangkaian sistem minimum ATmega328 dan modul GSM ditempatkan pada ruang tengah.

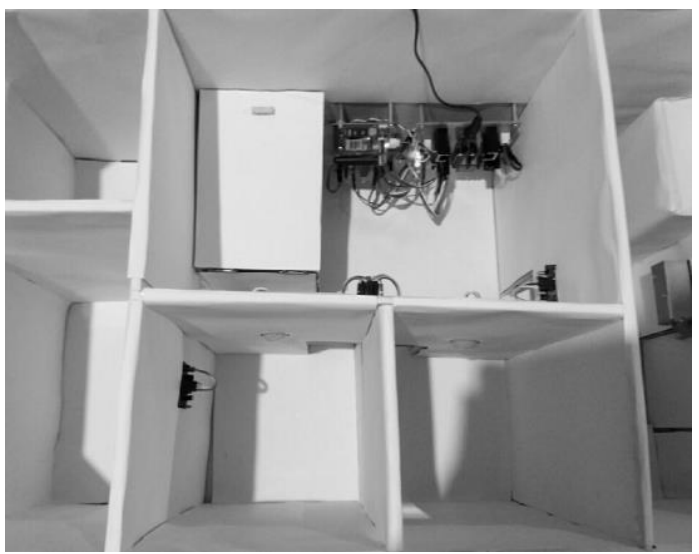

Gambar 4. Implementasi Sistem

\subsection{Pengujian Catu Daya}

Pengujian catu daya dilakukan untuk mengetahui berapa output tegangan yang dihasilkan dalam memberikan tegangan ke rangkaian sistem minimum ATmega328 dan beberapa rangkaian sensor input/output. Pada pembuatan alat ini penulis menggunakan dua buah catu daya yaitu adaptor DC $12 \mathrm{~V}$ dari sumber listrik PLN dan baterai aki (accu) 12V. Adaptor DC $12 \mathrm{~V}$ merupakan sumber tegangan utama, sedangkan baterai aki digunakan untuk membackup catu daya apabila sumber tegangan utama mati. Berikut ini adalah hasil dari pengujian catu daya tersebut:

Tabel 1. Pengujian Catu Daya

\begin{tabular}{|c|c|c|c|}
\hline No. & $\begin{array}{c}\text { Sumber } \\
\text { Tegangan }\end{array}$ & $\begin{array}{c}\text { Kunci } \\
\text { Solenoid }\end{array}$ & $\begin{array}{c}\text { Sistem } \\
\text { Minimum } \\
\text { dan Sensor }\end{array}$ \\
\hline 1. & $\begin{array}{c}\text { Adaptor } \\
12 \mathrm{~V}\end{array}$ & $12 \mathrm{~V}$ & $5 \mathrm{~V}$ \\
\hline 2. & $\begin{array}{c}\text { Baterai aki } \\
12 \mathrm{~V}\end{array}$ & $12 \mathrm{~V}$ & $5 \mathrm{~V}$ \\
\hline
\end{tabular}

Dari tabel diatas dapat disimpulkan bahwa rangkaian catu daya dari sumber adaptor $12 \mathrm{~V}$ PLN dan baterai aki $12 \mathrm{~V}$ berfungsi dengan baik karena menghasilkan output tegangan sesuai dengan kebutuhan yaitu $12 \mathrm{~V}$ untuk kunci solenoid dan $5 \mathrm{~V}$ untuk rangkaian sistem minimum ATmega328 dan beberapa sensor input/output.

\subsection{Pengujian Sensor RFID}

Pengujian sensor RFID bertujuan untuk mengetahui seberapa jauh jarak transmisi antara tag card RFID dengan RFID reader. Pengujian dilakukan dengan mendekatkan tag card RFID ke RFID reader dengan jarak tertentu kemudian diukur oleh mistar ukur. Berikut ini adalah hasil dari pengujian sensor RFID:

Tabel 2. Pengujian Sensor RFID

\begin{tabular}{|c|c|c|c|c|c|c|}
\hline \multirow{2}{*}{ No. } & Jarak & \multicolumn{6}{|c|}{ Kartu RFID } \\
\cline { 3 - 7 } & $(\mathrm{cm})$ & 1 & 2 & 3 & 4 & 5 \\
\hline 1. & $1 \mathrm{~cm}$ & 1 & 1 & 1 & 1 & 1 \\
\hline 2. & $2 \mathrm{~cm}$ & 1 & 1 & 1 & 1 & 1 \\
\hline 3. & $3 \mathrm{~cm}$ & 1 & 1 & 1 & 1 & 1 \\
\hline 4. & $4 \mathrm{~cm}$ & 1 & 1 & 1 & 1 & 1 \\
\hline 5. & $5 \mathrm{~cm}$ & 1 & 1 & 1 & 1 & 1 \\
\hline 6. & $6 \mathrm{~cm}$ & 0 & 0 & 0 & 0 & 0 \\
\hline 7. & $7 \mathrm{~cm}$ & 0 & 0 & 0 & 0 & 0 \\
\hline
\end{tabular}

Keterangan:

$1=$ Terdeteksi

$0=$ Tidak Terdeteksi

Dari tabel diatas dapat disimpulkan bahwa jarak maksimal pendeteksian tag card RFID ke RFID reader adalah $5 \mathrm{~cm}$, lebih dari itu maka RFID reader tidak bisa mendeteksi tag card.

\subsection{Pengujian Sensor Sentuh}

Pengujian sensor sentuh dilakukan dengan cara menyentuh sensor oleh tangan dan menghasilkan sinyal output ke kunci solenoid untuk mengontrol pintu rumah. Berikut ini adalah hasil dari pengujian sensor sentuh tersebut:

Tabel 3. Pengujian Sensor Sentuh

\begin{tabular}{|c|c|c|}
\hline No. & Pengujian & Hasil \\
\hline 1. & Sensor disentuh & Pintu terbuka \\
\hline 2. & Sensor tidak disentuh & Pintu terkunci \\
\hline
\end{tabular}

Dari tabel diatas dapat disimpulkan ketika sensor disentuh oleh tangan maka pintu rumah akan terbuka, sedangkan ketika sensor tidak disentuh maka pintu rumah akan terkunci.

\subsection{Pengujian Modul GSM Input}

Pengujian modul GSM input dilakukan dengan memberikan perintah SMS dari nomor handphone pemilik rumah untuk mengaktifkan atau menonaktifkan alarm. Berikut ini adalah hasil dari pengujian modul GSM input tersebut:

Tabel 4. Pengujian Modul GSM Input

\begin{tabular}{|c|l|c|}
\hline No. & \multicolumn{1}{|c|}{ Pengujian } & Hasil \\
\hline 1. & $\begin{array}{l}\text { Pemilik rumah mengirim } \\
\text { SMS alarm hidup }\end{array}$ & $\begin{array}{l}\text { Sensor PIR } \\
\text { aktif bekerja }\end{array}$ \\
\hline 2. & Pemilik rumah mengirim & Sensor PIR \\
\hline
\end{tabular}




\section{SMS alarm mat}

tidak aktif

Dari tabel diatas dapat disimpulkan ketika pemilik rumah mengirimkan SMS ke modul GSM dengan perintah alarm hidup maka sensor PIR akan aktif bekerja, sedangkan ketika pemilik rumah mengirimkan SMS dengan perintah alarm mati maka sensor PIR tidak aktif bekerja.

\subsection{Pengujian Sensor PIR}

Pengujian sensor PIR bertujuan untuk mengetahui seberapa jauh jarak sensor bisa mendeteksi pergerakan orang. Berikut ini adalah hasil dari pengujian sensor PIR tersebut:

Tabel 5. Pengujian Sensor PIR

\begin{tabular}{|c|c|c|c|c|c|}
\hline \multirow{2}{*}{ No. } & Jarak & \multicolumn{5}{|c|}{ Sensor PIR } \\
\cline { 3 - 6 } & Meter) & 1 & 2 & 3 & 4 \\
\hline 1. & $0,5 \mathrm{~m}$ & 1 & 1 & 1 & 1 \\
\hline 2. & $1 \mathrm{~m}$ & 1 & 1 & 1 & 1 \\
\hline 3. & $1,5 \mathrm{~m}$ & 1 & 1 & 1 & 1 \\
\hline 4. & $2 \mathrm{~m}$ & 1 & 1 & 1 & 1 \\
\hline 5. & $2,5 \mathrm{~m}$ & 1 & 1 & 1 & 1 \\
\hline 6. & $3 \mathrm{~m}$ & 1 & 1 & 1 & 1 \\
\hline 7. & $3,5 \mathrm{~m}$ & 1 & 1 & 1 & 1 \\
\hline 8. & $4 \mathrm{~m}$ & 1 & 1 & 1 & 1 \\
\hline 9. & $4,5 \mathrm{~m}$ & 1 & 1 & 1 & 1 \\
\hline 10. & $5 \mathrm{~m}$ & 0 & 0 & 0 & 0 \\
\hline 11. & $5,5 \mathrm{~m}$ & 0 & 0 & 0 & 0 \\
\hline
\end{tabular}

Keterangan:

$1=$ Terdeteksi

$0=$ Tidak Terdeteksi

Dari tabel diatas dapat disimpulkan bahwa jarak maksimal sensor PIR mendeteksi pergerakan orang adalah 4,5 meter, lebih dari itu sensor PIR tidak bisa mendeteksi.

\subsection{Pengujian Proses}

Pengujian proses bertujuan untuk mengetahui kinerja rangkaian sistem minimum ATmega328. Pengujian dilakukan dengan cara memberikan tegangan catu daya kepada rangkaian sistem minimum dan menghitung tegangan keluaran dari setiap pin mikrokontroler ATmega328. Berikut ini adalah hasil dari pengujian proses tersebut:

\section{Tabel 6. Pengujian Proses}

\begin{tabular}{|c|l|c|}
\hline No. & \multicolumn{1}{|c|}{ Pin Mikrokontroler } & Hasil \\
\hline 1. & Pin 7, 20 dan 21 (VCC) & 5V \\
\hline 2. & Pin 8 dan 22 (GND) & OV \\
\hline 3. & Pin 4 (Input/Output) & $5 \mathrm{~V}$ \\
\hline 4. & Pin 5 (Input/Output) & $5 \mathrm{~V}$ \\
\hline 5. & $\begin{array}{l}\text { Pin 6, 11, 12, 13, 14, 15, 16, } \\
17,18 \text { dan 19 (Input) }\end{array}$ & 0V \\
\hline 6. & $\begin{array}{l}\text { Pin 23, 24, 25, 26, 27 dan 28 } \\
\text { (Output) }\end{array}$ & $5 \mathrm{~V}$ \\
\hline
\end{tabular}

Dari tabel hasil pengukuran diatas dapat disimpulkan bahwa pengujian proses rangkaian sistem minimum ATmega328 berjalan dengan baik. Tegangan pin input menghasilkan OV karena sumber tegangan diperoleh dari sensor input untuk mengirimkan sinyal ke mikrokontroler, sedangkan tegangan pin output menghasilkan 5V untuk mengirimkan sinyal dari mikrokontroler ke sensor output.

\subsection{Pengujian Kunci Solenoid}

Pengujian kunci solenoid dilakukan dengan cara menempelkan kartu RFID atau menyentuh sensor sentuh oleh tangan. Berikut ini adalah hasil dari pengujian kunci solenoid tersebut:

Tabel 7. Pengujian Kunci Solenoid

\begin{tabular}{|c|l|c|}
\hline No. & \multicolumn{1}{|c|}{ Pengujian } & Hasil \\
\hline 1. & $\begin{array}{l}\text { Akses kartu RFID } \\
\text { diterima }\end{array}$ & Kunci terbuka \\
\hline 2. & Sensor disentuh & Kunci terbuka \\
\hline
\end{tabular}

Dari tabel diatas dapat disimpulkan bahwa kunci solenoid akan terbuka apabila akses kartu RFID diterima atau sensor disentuh.

\subsection{Pengujian LCD}

Pengujian LCD dilakukan dengan cara memverifikasi setiap kartu RFID yang ditempelkan pada RFID reader. Berikut ini adalah hasil dari pengujian LCD tersebut:

Tabel 8. Pengujian LCD

\begin{tabular}{|c|l|l|}
\hline No. & \multicolumn{1}{|c|}{ Pengujian } & \multicolumn{1}{c|}{ Hasil } \\
\hline 1. & $\begin{array}{l}\text { Akses kartu RFID } \\
\text { master }\end{array}$ & $\begin{array}{l}\text { LCD menampilkan } \\
\text { kartu RFID master }\end{array}$ \\
\hline 2. & $\begin{array}{l}\text { Akses kartu RFID } \\
\text { diterima }\end{array}$ & $\begin{array}{l}\text { LCD menampilkan } \\
\text { kartu RFID diterima }\end{array}$ \\
\hline 3. & $\begin{array}{l}\text { Akses kartu RFID } \\
\text { ditolak }\end{array}$ & $\begin{array}{l}\text { LCD menampilkan } \\
\text { kartu RFID ditolak }\end{array}$ \\
\hline
\end{tabular}

Dari tabel diatas dapat disimpulkan bahwa LCD akan menampilkan status sesuai dengan verifikasi kartu RFID yang ditempelkan pada RFID reader.

\subsection{Pengujian LED}

Pengujian LED dilakukan dengan cara memverifikasi setiap kartu RFID yang ditempelkan pada RFID reader. Berikut ini adalah hasil dari pengujian LED tersebut:

\section{Tabel 9. Pengujian LED}

\begin{tabular}{|c|l|l|}
\hline No. & \multicolumn{1}{|c|}{ Pengujian } & \multicolumn{1}{c|}{ Hasil } \\
\hline 1. & $\begin{array}{l}\text { Akses kartu } \\
\text { RFID master }\end{array}$ & $\begin{array}{l}\text { LED biru dan hijau } \\
\text { menyala }\end{array}$ \\
\hline 2. & $\begin{array}{l}\text { Akses kartu } \\
\text { RFID diterima }\end{array}$ & LED hijau menyala \\
\hline 3. & $\begin{array}{l}\text { Akses kartu } \\
\text { RFID ditolak }\end{array}$ & LED merah menyala \\
\hline
\end{tabular}


Dari tabel diatas dapat disimpulkan bahwa LED akan menyala sesuai dengan verifikasi kartu RFID yang ditempelkan pada RFID reader.

\subsection{Pengujian Modul GSM Output}

Pengujian modul GSM output dilakukan dengan cara mengaktifkan alarm dan sensor PIR mendeteksi pergerakan orang didalam rumah. Berikut ini adalah hasil dari pengujian modul GSM output tersebut:

Tabel 10. Pengujian Modul GSM Output

\begin{tabular}{|c|l|l|}
\hline No. & \multicolumn{1}{|c|}{ Pengujian } & \multicolumn{1}{c|}{ Hasil } \\
\hline 1. & $\begin{array}{l}\text { Ada pergerakan } \\
\text { orang }\end{array}$ & $\begin{array}{l}\text { Modul GSM } \\
\text { mengirimkan SMS }\end{array}$ \\
\hline 2. & $\begin{array}{l}\text { Tidak ada } \\
\text { pergerakan orang }\end{array}$ & $\begin{array}{l}\text { Modul GSM tidak } \\
\text { mengirimkan SMS }\end{array}$ \\
\hline
\end{tabular}

Dari tabel diatas dapat disimpulkan ketika alarm dalam keadaan hidup dan sensor PIR mendeteksi pergerakan orang didalam rumah maka modul GSM akan mengirimkan SMS peringatan tanda bahaya ke nomor handphone pemilik rumah.

\subsection{Pengujian Buzzer}

Pengujian buzzer dilakukan dengan cara mengaktifkan alarm dan sensor PIR mendeteksi pergerakan orang didalam rumah. Berikut ini adalah hasil dari pengujian buzzer tersebut:

Tabel 11. Pengujian Buzzer

\begin{tabular}{|c|l|c|}
\hline No. & \multicolumn{1}{|c|}{ Pengujian } & Hasil \\
\hline 1. & $\begin{array}{l}\text { Ada pergerakan } \\
\text { orang }\end{array}$ & Buzzer hidup \\
\hline 2. & $\begin{array}{l}\text { Tidak ada } \\
\text { pergerakan orang }\end{array}$ & Buzzer mati \\
\hline
\end{tabular}

Dari tabel diatas dapat disimpulkan ketika alarm dalam keadaan hidup dan sensor PIR mendeteksi pergerakan orang didalam rumah, maka buzzer akan menyala sebagai peringatan tanda bahaya.

\section{Kesimpulan}

Berdasarkan perancangan dan pembahasan yang telah diuraikan, maka penulis dapat menyimpulkan bahwa perancangan sistem keamanan rumah menggunakan teknologi RFID, sensor PIR dan modul GSM berbasis mikrokontroler ATmega328 telah berhasil dibuat. Semua komponen rangkaian input, proses dan output berfungsi dengan baik dan sesuai dengan yang diharapkan. Penggunaan kunci solenoid dengan teknologi RFID sangat memungkinkan untuk mengganti kunci konvesional yang ada, sehingga kunci pintu rumah sangat sulit diduplikat. Hal ini terjadi karena untuk membuka pintu rumah harus menggunakan kartu RFID yang telah didaftarkan pada sistem mikrokontroler. Dalam keadaan alarm hidup, mikrokontroler akan mengaktifkan sensor PIR untuk bekerja mendeteksi pergerakan orang didalam rumah. Apabila ada pergerakan orang didalam rumah, maka sensor PIR akan mengirimkan sinyal ke mikrokontroler untuk mengeluarkan bunyi alarm sebagai tanda bahaya dan mengirimkan SMS peringatan ke nomor handphone pemilik rumah sehingga pelaku kejahatan yang memaksa masuk kedalam rumah akan mengurungkan niatnya untuk mencuri.

Saran-saran yang terkait dengan penelitian sistem keamanan rumah ini untuk pengembangan selanjutnya adalah alat yang dipasang untuk membuka atau mengunci pintu masih menggunakan teknologi RFID. Kedepannya diharapkan menggunakan teknologi sidik jari atau sensor retina mata, penambahan kamera ditiap ruangan sehingga pelaku kejahatan yang masuk kedalam rumah bisa terekam, penambahan fitur monitoring menggunakan jaringan internet agar pemilik rumah dapat mengontrol rumah dari jarak jauh.

\section{Referensi}

Angga, R. (2015). Pengertian Komponen Aktif dan Pasif Beserta Jenis dan Fungsinya. Diambil dari: http://skemaku.com/pengertiankomponen-aktif-dan-pasif-besertajenis-dan-fungsinya/. (7 Mei 2017).

Asad, M. R., Nurhayati, O. D., \& Widianto, E. D. (2015). Sistem Pengamanan Pintu Rumah Otomatis via SMS Berbasis Mikrokontroller Atmega328p. ISSN: 2338-0403. Semarang: Jurnal Teknologi dan Sistem Komputer Vol.3, No.1 Januari 2015: 1-7.

Masinambow, V., Najoan, M. E., \& Lumenta, A. S. (2014). Pengendali Saklar Listrik Melalui Ponsel Pintar Android. ISSN: 2301-8402. Manado: E-Journal Teknik Elektro dan Komputer 2014: 1-9 
Purnomo, E. (2015). Bahasa C Untuk Mikrokontroler AVR. Diambil dari: http://www.nulisilmu.com/2015/10/bahasa-c-untukmikrokontroler-avr.html. (7 Mei 2017)

Rerungan, J., Nugraha, D. W., \& Anshori, Y. (2014). Sistem Pengaman Pintu Otomatis Menggunakan Radio Frequency Identification (RFID) Tag Card dan Personal Identification Number (PIN) Berbasis Mikrokontroller AVR Atmega 128. ISSN 2356-4792. Sulawesi Tengah: Jurnal MEKTRIK Vol. 1, No. 1 September 2014: 20-28.

Sulistyowati, R., \& Febriantoro, D. D. (2012). Perancangan Prototype Sistem Kontrol dan Monitoring Pembatas Daya Listrik Berbasis Mikrokontroler. Surabaya: Jurnal IPTEK Vol.16 No,1 Mei 2012

Statistik, B. P. (2016). Statistik Kriminal 2016. Jakarta: Badan Pusat Statistik (BPS).

R. (2015). Rancang Bangun Sistem Keamanan Rumah Menggunakan Sensor PIR (Passive Infrared) dan SMS Sebagai Notifikasi. ISSN: 2301-8402. Manado: E-Journal Teknik Elektro dan Komputer Vol. 4, No. 6 2015: 10-15.

Riyadi, S., \& Purnama, B. E. (2013). Sistem Pengendalian Keamanan Pintu Rumah Berbasis SMS (Short Message Service) Menggunakan Mikrokontroler Atmega 8535. ISSN: 2302-5700. Jurnal IJNS (Indonesian Journal on Networking and Security) Vol. 2, No. 4 Oktober 2013: 7-11.

Undala, F., Triyanto, D., \& Brianorman, Y. (2015). Prototype Sistem Keamanan Pintu Menggunakan Radio Frequency Identification (RFID) Dengan Kata Sandi Berbasis Mikrokontroler. ISSN : 2338-493X. Pontianak: Jurnal Coding Sistem Komputer Untan Vol. 03, No. 1 2015: 30-40. 